\title{
CORONARY ARTERY DISEASE;
}

RELATIONSHIP OF BODY MASS INDEX AND SEVERITY OF CORONARY ARTERY DISEASE IN PATIENTS UNDERGOING CORONARY ANGIOGRAPHY.

1. MBBS, FCPS (Cardiology) Assistant Professor Department of Cardiology, Chaudhry Pervaiz Elahi Institute of Cardiology, Multan

2. MBBS, FCPS (Medicine)

Assistant Professor

Department of Medicine, Medical Unit-III

Nishtar Medical University, Multan.

3. MBBS, FCPS (Medicine)

Assistant Professor

Department of Medicine

Nishtar Medical University, Multan.

4. M.Phil

Senior Research Officer

PHRC, Research Centre

Nishtar Medical University, Multan.

5. MBBS

House Officer

Nishtar Medical University, Multan.

Correspondence Address:

Dr. Shahzad Alam Khan

Assistant Professor

Department of Medicine

Nishtar Medical University, Multan.

shahzadalam17735@gmail.com

Article received on:

30/07/2018

Accepted for publication:

20/12/2018

Received after proof reading:

23/02/2019

\section{Muhammad Ikram Farid ${ }^{1}$, Nasir Jamal Khan², Shahzad Alam Khan ${ }^{3}$, Iqra Imtiaz ${ }^{4}$, Sohail Safdar ${ }^{5}$}

ABSTRACT... Objectives: To establish or refute any association between high Body Mass Index (BMI) and Coronary Artery Disease in South Punjab area of Pakistan. Background: Ischemic heart disease has a strong relation with high Body Mass Index (BMI). But still uncertainty persists about the association that exists between overweight (BMI 25-29.9 $\mathrm{kg} / \mathrm{m}^{2}$ ) or obese patients $\left(B M I>30 \mathrm{~kg} / \mathrm{m}^{2}\right.$ ). Design: Observational, Cross Sectional Study. Setting: Cardiac cath lab department of Multan Institute of cardiology Multan. Duration of Study: Six month tenure extending between January 2017 to June 2017. Methods: The study was conducted in cardiac cath lab department of Multan Institute of cardiology, Multan. Total of Four hundred and seventy eight patients (478) over a period of two months were included in the study. All patients were having a coronary angiography due to a medical indication. Their BMI was calculated by using standard formula. Results: Out of 478 patients $335(70.1 \%)$ patients were having optimal weight. $123(25.7 \%)$ were overweight, $12(2.5 \%)$ were mildly obese, $8(1.7 \%)$ were severely obese patients. Optimal weight patients had $12.5 \%$ normal coronary angiogram, $26.3 \%$ had single vessel CAD, $20 \%$ had two vessel disease and $41.2 \%$ had severe triple vessel disease. Over weight patients had $17.9 \%$ normal coronary angiograms, single vessel CAD was seen in $26.8 \%$ patients, $21.9 \%$ patients had two vessel disease and $33.3 \%$ had severe triple vessel CAD. Mildly obese patients had $8.3 \%$ normal coronary angiograms, 50\% had single vessel CAD, 25\% had two vessel disease, and 16.7\% had severe Triple vessel disease. Among severe obese patients $12.5 \%$ had normal coronary angiography, $25 \%$ had single vessel disease, $50 \%$ had two vessel disease, and $12.5 \%$ had severe triple vessel disease. Conclusion: Patients undergoing Coronary Angiogram in the region of south Punjab did not show any significant relationship between severity of CAD (Severe two vessels \& severe Triple vessel disease) and BMI.

Key words: Body Mass Index, Coronary Artery Disease, Two Vessel Disease, Tripple Vessel Disease.

Article Citation: Farid MI, Khan NJ, Khan SA, Imtiaz I, Safdar S. Coronary artery disease; relationship of body mass index and severity of coronary artery disease in patients undergoing coronary angiography. Professional Med J 2019; 26(3):493-497. DOI: 10.29309/TPMJ/2019.26.03.3262

\section{INTRODUCTION}

Obesity is a disastrous problem worldwide. Its frequency has increased twofold since 1980. A survey done in 2005 estimated that 1.3 billion of world population is obese. It suggested $23 \%$ of adults more than 20 years to be overweight $(\mathrm{BMI}>25)$ and $10 \%$ having obesity $(\mathrm{BMI}>30) .^{1,2}$ According to World Health organization report approximately 1.9 billion adults are overweight. Out of these approximately 600 million are obese. In Chinese population sample the frequency of $\mathrm{BMI}$ above 25 has risen beyond $50 \%$ in men and women. ${ }^{1}$ Explanations for this rapid trajectory are complex; they include modification in dietary habits, physical activity, and urbanization. Popkin and Gordon-Larsen have identified that use of edible oils, caloric sweeteners, and animal source foods is showing up rise trend.

Although obesity is thought to be a potential risk factor for CAD, but many recent studies and published literature has indicated that its presence may have an inverse relationship with CAD. This finding of obesity paradox has been observed more in survival of patients of congestive cardiac failure and in patients following a coronary revascularization procedure. This finding has generated a lot of debate recently. This finding was never studied in the region of South of Punjab and we wanted to know whether this finding holds 
good for our region or not.

BMI can be easily calculated by weight for height ratio. It's mentioned as a person's weight in kilograms divided by the square of height in meters $\left(\mathrm{kg} / \mathrm{m}^{2}\right)$. Any individual who has BMl of 25 or greater is overweight, and if his BMI is 30 or more that person is considered obese. This tool is best for population based studies for all ages and sex. High BMI is a disastrous factor for Cardiovascular diseases especially stroke and CAD.

Rising trend of obesity in childhood and sedentary living has already caused increased prevalence of Diabetes Mellitus and hypertension in younger age groups, ${ }^{4,5}$ Diabetes, rheumatologic disorders specially osteoarthritis and some malignancies like breast, ovarian, endometrial, prostate, liver and gall bladder malignancies are also attributed to obesity. Our main objective was to determine the severity of CAD in obese patients presenting to Cardiac catheterization laboratory of Chaudhry Pervaiz Elahi Institute of Cardiology.

We divided the patients into one group of nonsignificant CAD patients who had no or minimal disease on Angiography. Single vessel disease, severe two vessel disease and severe triple vessel disease patients were categorized in different groups. For the sake of comparison we included patients of both two vessel and triple vessel disease in single category of severe CAD, while patients with minimal or no disease were kept in another group.

\section{METHODS}

The Observational, Cross Sectional study was conducted in cardiac cath lab department of Multan Institute of cardiology, Multan.

\section{Data Collection Procedure}

A proforma was made to note the findings of the patients. All the patients having ischemic heart disease (478), undergoing coronary angiography were enrolled from cath lab of Multan Institute of Cardiology Multan. Proper permission was issued by Institutional Ethical Committee to conduct this study. After taking proper informed consent from each patient, that case was considered for this study and was properly informed about objectives of this study. All patients underwent a coronary angiography due to a medical indication. All patients' height and weight were recorded on the day of Coronary angiography and BMI was calculated. Patients were divided into subsets of Optimal weight (BMl<25kg/m2), Overweight (BMI $25-29.9 \mathrm{~kg} / \mathrm{m} 2$ ), mildly obese (BMI 30-34.9kg/m2) and severely obese $(\mathrm{BMI}>35 \mathrm{~kg} / \mathrm{m} 2)$. Severity of Coronary Artery Disease (CAD) was also divided into Non significant CAD, Single vessel CAD, Two vessel CAD and Triple vessel CAD. All the data was recorded on a pre-designed questionnaire.

\section{Data Analysis}

Data was processed and analyzed by SPSS-20. Descriptive statistics were used for the calculation of mean and standard deviation for the patients age, height, weight. Frequencies were estimated for different BMI levels. Frequencies of various BMl subsets was also plotted against subsets of CAD severity.

\section{RESULTS}

Our study cohort comprised 103 female and 375 male. Mean age of patients was $48 \pm 9$ with youngest patient 34 years old and eldest to be 69 years old. Of these 478 patients 335 (70.1\%) patients were having optimal weight. $123(25.7 \%)$ were overweight, 12 (2.5\%) were mildly obese, 8 $(1.7 \%)$ were severely obese patients.

Optimal weight patients had $12.53 \%$ normal coronary angiogram, $26.26 \%$ had single vessel CAD, $20 \%$ had two vessel disease and $41.2 \%$ had severe triple vessel disease.

Over weight patients had $17.9 \%$ normal coronary angiograms, single vessel CAD was seen in $26.8 \%$ patients, $21.9 \%$ patients had two vessel disease and $33.3 \%$ had severe triple vessel CAD.

Mildly obese patients had $8.3 \%$ normal coronary angiograms, $50 \%$ had single vessel CAD, $25 \%$ had two vessel disease and $16.7 \%$ had severe triple vessel disease. Among severe obese patients $12.5 \%$ had normal coronary angiography, 25\% had single vessel disease, $50 \%$ had two vessel 
disease, and $12.5 \%$ had severe triple vessel disease.

When severe Two vessel and triple vessel disease was combined it was noted that $61.2 \%$ of optimal weight patients had it. In over weight patients it was $55.3 \%$. Mildly obese patients severe two vessel \& triple vessel disease was seen in $41.7 \%$. In the category of severely obese patients severe two vessel and triple vessel disease was seen in $62.5 \%$.

\begin{tabular}{|l|c|c|c|}
\hline & Freq & \%age & Cummu \% \\
\hline $\begin{array}{l}\text { Optimal Weight: BMI< } \\
25 \text { kg/ m2 }\end{array}$ & 335 & 70.1 & 70.1 \\
\hline $\begin{array}{l}\text { Overweight: BMI 25-9.9 } \\
\text { kg/m2 }\end{array}$ & 123 & 25.7 & 95.8 \\
\hline $\begin{array}{l}\text { Mildly Obese: BMI 30- } \\
34.9 \text { kg/m2 }\end{array}$ & 12 & 2.5 & 98.3 \\
\hline $\begin{array}{l}\text { Severely Obese: BMI> } \\
35 \text { kg/m2 }\end{array}$ & 8 & 1.7 & 100.0 \\
\hline & Table-I & \\
\hline
\end{tabular}

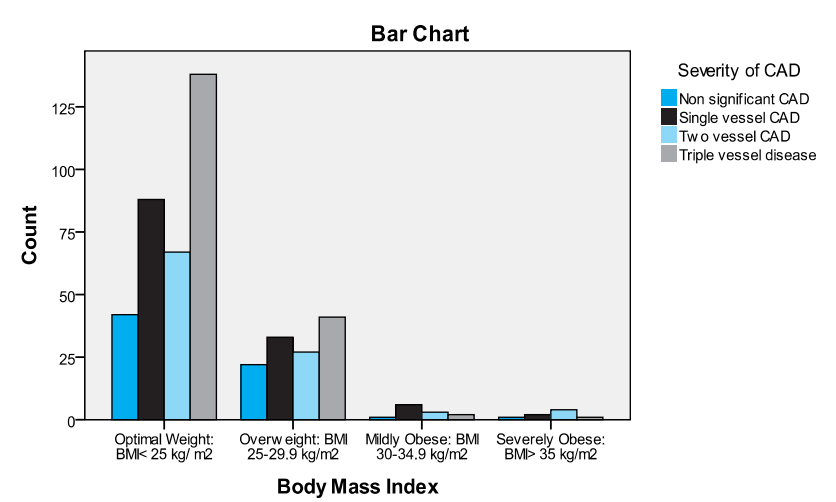

Figure-1

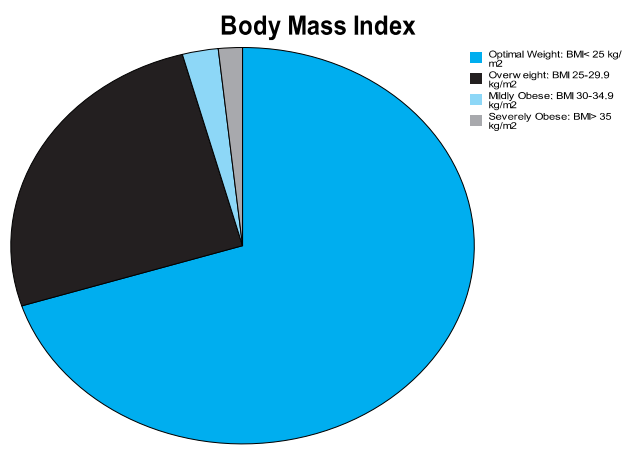

Figure-2

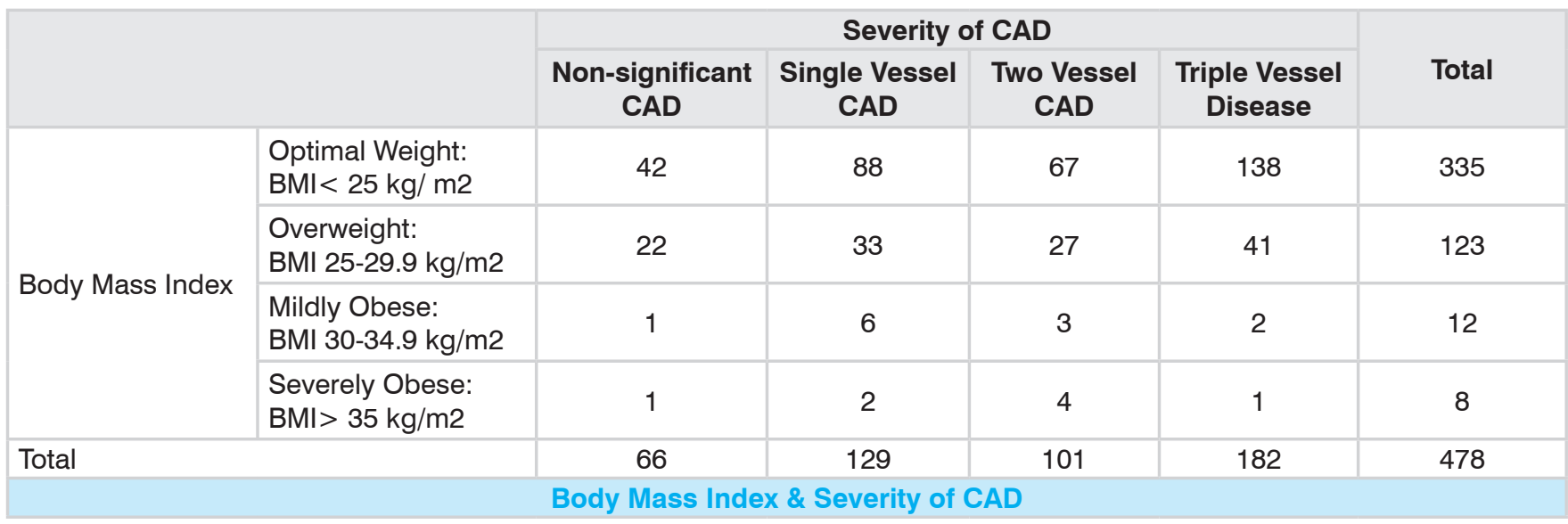

\section{DISCUSSION}

The novel and important aspect of this study was that no association was established between high BMI with severity of CAD in our study population set. Double \& Triple vessel disease (2VD \& TVD) was equally common in obese patients as it was in normal weight patients. Positive relationship between incremental rise in BMl and worsening severity of CAD could not be ascertained in our study.
Although obesity has strong relation with metabolic syndrome with resultant increase in insulin resistance and high BP, yet we could not identify any significant differences when it came to studying the coronary angiograms of these patients.

The mechanisms which explain any relation between obesity and CAD severity are yet to be determined and open for discussion. Inflammation, metabolic syndrome \& hyperlipidemia are all 
thought to be increased in obese patients and may be a causative agent, still in our obese patients subset it did not resulted in untoward effects in causing the coronary anatomy.

Recent data has spoken volume of an "Obesity Paradox", meaning that obese patients who undergo coronary revascularization have a better short term outcomes and survival in certain subsets of patients. In particular, obese patients with congestive cardiac failure had a better outcome. "Obesity Paradox" in CAD has few understandable explanations. These obese patients with CAD usually come to notice at an earlier age with a lower plaque load. ${ }^{6-8}$ It may be because of a referral bias where only the healthiest obese patients who may have lower disease severity are included in cohorts demonstrating the obesity paradox. The follow-up intervals may also be of shorter length to capture the longterm negative influences of obesity. ${ }^{9}$ Another limiting factor may be how we quantify adiposity by BMI. For example 'normal weight' is defined as BMI range of $18.5-24.9 \mathrm{~kg} / \mathrm{m} 2$ which may be too broad and the lower end of this classification may actually be indicative of unhealthy levels of decreased body mass. But recently few more investigations showed that the obesity paradox exists for both BMI and body fat, with higher body fat being an independent predictor of better survival. ${ }^{10-12}$

\section{CONCLUSION}

We failed to establish any significant relationship between severity of CAD (Severe two vessels \& severe Triple vessel disease) and BMI. However due to limitation of time and loss of follow up was a major constraint in establishing "Obesity Paradox".

Copyright(C 20 Dec, 2018.

\section{REFERENCES}

1. Popkin BM, Gordon-Larsen P. The nutrition transition: Worldwide obesity dynamics and their determinants. Int J Obes Relat Metab Disord 2004; 28(Suppl 3): S2.

2. Kelly T, Yang W, Chen CS. Global burden of obesity in 2005 and projections to 2030. Int $\mathrm{J}$ Obes (Lond) 2008; 32: 1431.

3. Gaziano JM. Fifth phase of the epidemiologic transition: The age of obesity and inactivity. JAMA 2010; 303: 275.

4. Hannon TS, Rao G, Arslanian SA. Childhood obesity and type 2 diabetes mellitus. Pediatrics 2005; 116: 473.

5. Muntner P, He J, Cutler JA. Trends in blood pressure among children and adolescents. JAMA 2004; 291:2107.

6. Oreopoulos A, McAlister FA, Kalantar-Zadeh K. The relationship between body mass index, treatment, and mortality in patients with established coronary artery disease: A report from Approach, Eur Heart $\mathrm{J}$ 2009; 30: 2584-92.

7. Niraj A, Pradhan J, Fakhry H. Severity of coronary artery disease in obese patients undergoing coronary angiography. Clin Cardiol, 2007; 30: 391-6.

8. Rubinshtein R, Halon DA, Jaffe R. Relation between obesity and severity of coronary artery disease in patients undergoing coronary angiography, Am J Cardiol 2006; 97: 1277-80.

9. Oreopoulos A, Padwal R, Norris CM. Effect of obesity on short- and long-term ortality postcoronary revascularization: A meta-analysis, Obesity (Silver Spring), 2008; 16: 442-50.

10. Lavie CJ, Milani RV, Artham SM. The obesity paradox, weight loss, and coronary disease, Am J Med 2009; 122: 1106-14.

11. DeSchutter A, Lavie CJ, Milani RV. Body composition and mortality in patients with coronary heart disease. Circulation, 2010; 122: A114-22.

12. DeSchutter A, Lavie CJ Jr, Milani RV. Body fat and mortality in patients with coronary heart disease: The "obesity 


\title{
Impossible is a word to be found only in the dictionary of fools.
}

\author{
"Napoleon Bonaparte"
}

\begin{tabular}{|c|c|c|c|}
\hline \multicolumn{4}{|c|}{ AUTHORSHIP AND CONTRIBUTION DECLARATION } \\
\hline Sr. \# & Author-s Full Name & Contribution to the paper & Author $=$ s Signature \\
\hline 1 & M. Ikram Farid & $\begin{array}{l}\text { Concept, Planning, Data } \\
\text { collection. }\end{array}$ & \\
\hline 2 & Nasir Jamal Khan & Data collection and analysis. & Nhsin \\
\hline 3 & Shahzad Alam Khan & Data analysis. & \\
\hline 4 & Iqra Imtiaz & Coordinator \& Proof reader. & lapaliog \\
\hline 5 & Sohail Safdar & Proof reading, Statistical review. & Sulu's. \\
\hline
\end{tabular}

